\title{
Agglomeration and growth in knowledge-based societies: an introduction to this special issue
}

\author{
Johannes Bröcker • Rüdiger Soltwedel
}

Received: 23 January 2009 / Accepted: 23 January 2009 / Published online: 17 February 2009

(C) Springer-Verlag 2009

The five papers collected in this issue are selected from the contributions to a workshop on "Agglomeration and growth in knowledge-based societies", held April 2007 at the Institute for the World Economy in Kiel.

The title of the workshop does more than just pointing to a subject of research; it makes a statement about what we believe to be true, based on a long-lasting stream of research that goes back to Alfred Marshall and to the less well known Wilhelm Roscher, a representative of the German Historical School: Agglomeration, knowledge creation and growth are related phenomena. Growth in modern highly developed societies is first and foremost growth of knowledge that is transformed into marketable products and services. Innovation is the driving force, capital accumulation, which stood in the focus of Solovian growth theory, just follows the pace dictated by knowledge creation. Urban agglomerations are both, seed beds of new ideas as well as schools, that is locations where people cluster in order to learn most effectively and efficiently, what other people already know.

The intimate relation between agglomeration on the one hand and knowledge creation and learning on the other is supported by a still growing body of literature accumulating empirical evidence, with more and more informative data sets being compiled and methodological advances allowing better and better to detect spurious correlations and fallacies from neglecting joint endogeneity or spatial

\footnotetext{
J. Bröcker $(\varangle)$

Institut für Regionalforschung, Christian-Albrechts-Universität, Ohlshausenstraße 40, 24098 Kiel, Germany

e-mail: broecker@economics.uni-kiel.de

R. Soltwedel

The Kiel Institute for the World Economy, Düsternbrooker Weg 120, 24105 Kiel, Germany

e-mail: ruediger.soltwedel@ifw-kiel.de
} 
autocorrelation. Even though methodological progress made us more critical, i.e. less willing to regard a relation extracted from the data as significant, the sharper methods applied to available data strengthened rather than weakened our belief that agglomeration, knowledge and growth are non-separable phenomena. They form the vertices of a triangle, whose edges represent causal relations going both ways.

In this field of research, evidence came first, and theory tried to keep up, eventually leading to a deeper insight into the basic economic mechanisms generating the patterns observed. Market imperfections are the key to understand how knowledge, agglomeration and growth are related. Only because prices are not driven down to marginal costs can operating profits be realised in the market, that remunerate the innovator, and only because knowledge diffusion is not perfect and costless can these profits be sustained. Thus, market imperfections are necessary for growth, but also generate all the allocation problems that we teach our students: underutilization of ideas, for which one has to pay in spite of non-rivalry, adverse selection and moral hazard due to information asymmetry, lacking innovation incentive due to non-excludability and so on. Agglomerations can be understood as social arrangements which allow mitigating such allocation problems, thus enhancing the efficiency of the innovation process for the economy as a whole.

Given that there is so much theoretical and empirical progress in studying the field, what remains to be added? Though we know growth, knowledge and agglomeration to be intimately connected and though theory tells us the economic principles behind, our knowledge is not yet sufficiently concrete to be useful for either reliable predictions or policy advices. Policy instruments are specific by nature; recommending to "foster knowledge creation", say, is a slogan, not an advice. Policy makers have to decide, for example, whether to extend university capacity, and if so, where to locate the capacity, which disciplines to focus on, or whether instead they should pump more public money into subsidizing private innovation activity. If the region that a policy maker is responsible for turns out to be less innovative than others, he or she would like to know if this is due to regional characteristics that are hard to influence such as sectoral specialization, or factors that are to some extent under his or her control. In other words, more concrete research results are needed regarding the relation between the vertices of the triangle mentioned above.

The five papers collected in this volume are far from closing the gap, but they try to add a few pieces of empirical evidence sharpening the picture and adding concreteness to our understanding of knowledge creation and diffusion. The spatial perspective is crucial to all of them.

Florian Lehmer and Joachim Möller exploit a rich data set for Germany in a careful way to identify and quantify the impact of firm size and urbanity on wages. The urban wage premium per se is a well established fact known from macro data. Such data do not allow however to disentangle what is behind this premium. Is it that big firms, overrepresented in big cities, pay more, or does a premium remain after controlling for firm size? Do firms in larger agglomerations pay more because they select higher skilled workers, or do workers acquire higher skills because they work in a big city? Similarly, do big firms pay more because they select higher skills than small ones, or do workers learn more in larger firms? Different answers to these questions lead to very different perceptions of the agglomeration-knowledge nexus. Lehmer and Möller 
look at individuals with rich variation of attributes and - in addition-with attributes even changing over time, with workers moving from a rural to an urban environment or changing from a small firm to a large one, for example. The authors find an urban wage growth effect showing that there is a positive knowledge externality operating on the urban level and not just within firms.

Rui Baptista and Joana Mendonça tackle with new data an old question, whether proximity to knowledge sources influences locational choice of knowledge based startups. As expected, the general answer is affirmative; but this is not all. What they are able to add to a general picture is the detailed anatomy of this nexus. Regarding startups, they differentiate between medium and high-tech manufacturing on the one hand and knowledge-intensive services on the other. Regarding knowledge sources, they distinguish between number of universities, number of graduates and number of students as well as between disciplines, finding rather different results for manufacturing and services. One of their findings is that for manufacturing, skill supply in basic sciences and engineering matters most, while in services the specific discipline of university graduates plays no role.

David Audretsch, Dirk Dohse and Annekatrin Niebuhr combine in their paper the knowledge spillover theory of entrepreneurship with the diversity argument from urban economics to explain regional differences in new firm formation. They find evidence for the hypothesis that regions with a high level of R\&D and human capital provide more opportunities for entrepreneurship than other regions and that regional diversity has a crucial impact on start-up activity. Moreover, they are able to show that the determinants of new firm formation differ significantly with respect to the technology level and that it is therefore necessary to distinguish start-ups at different technological levels.

A particularly interesting result of their analysis - with a view at the ongoing debate about the empirical relevance of Marshall-Arrow-Romer (MAR) externalities versus Jacobs externalities - is their result that cultural diversity has a positive and highly significant impact on new firm formation while sectoral diversity tends to exert a negative effect. Their conclusion that the diversity of people is indeed more conducive to entrepreneurship than the diversity of firms reflects a sort of Kirznerian perspective of entrepreneurship that can be read out of their very clear and transparent analysis of what the theory says about the knowledge filter and its regional dimension. This methodologically sound paper is original in combining so far unrelated theoretical approaches, in proposing new and more adequate measures of ethnic and cultural diversity and in making use of a unique database on cultural diversity in Germany.

The MAR-Jacobs externalities debate is also the focus of the paper by Michael Fritsch and Viktor Slavtchev. They analyse the relationship between the specialisation of a region in certain industries and the efficiency of the regions (counties and Regional Planning Regions) in Germany, West and East, in generating new knowledge, using patent applications as the indicator of innovative output. Their results show that both MAR and Jacobs externalities affect the efficiency of regions in producing innovative output. There is evidence of the benefits of specialisation, up to a point: the relationship between specialisation and the performance of a region is hump-shaped-specialisation beyond a certain level does not enhance the efficiency of the regional innovation system. On the other hand, also a great diversity of the region's industrial portfolio is 
associated with a relatively low level of efficiency. Hence, region specific as well as industry specific factors have to be taken into account by policy makers. The upshot of their analysis for policy is that there are no one-size-fits-all policy recommendations for fostering the innovation output in all kinds of regions.

Bart Verspagen uses spatial correlation analysis, spatial principal components analysis and cluster analysis to provide an image of what kinds of regions innovate, and at what level, in the EU. The paper offers a valuable methodological contribution in the field of regional growth and technological change. Its core consists of a taxonomic approach that makes use of a wide array of indicators (both from standard statistics sources and from the European Patent Office database).

The results of the analysis of 'archetypical' regional development patterns suggest that there is a major spatial divide in Europe, with South and East Europe being at a lower general development level. This finding is certainly food for thought (and a call for action) for the regional policy makers, both within the respective countries themselves and at the EU level. It is particularly interesting that the educational level of the labour force and the urbanization factor i.e. population density and the service provision in education, health and business give the Eastern European regions a competitive edge over the Southern periphery of Europe in absorbing foreign technologies in a much more effective way; thus, they seem to be better placed in the European hierarchy of economic growth and development. The results presented in this paper harness the recognition that different policy instruments are warranted to enhance growth (which requires 'strengthening the strong') and to foster the catchup process of lagging regions with structural problems. There seems to be a marked trade-off between competitiveness and cohesion. Against the backdrop of these competing goals Verspagen suggests that spatial idiosyncrasies should explicitly be considered as a criterion in the Structural Funds of the European Union. 